\title{
COMPUTER ANALYSIS OF SOME CAT PARAHIPPOCAMPAL UNIT FIRING PATTERNS
}

\section{PETER COYLE}

Department of Anatomy, 5714 Medical Science II, The University of Michigan, Ann Arbor, Mich. 48104 (U.S.A.)

(Accepted September 17th, 1969)

\section{INTRODUCTION}

Distinguishing features of neuronal firing patterns may only become evident following an analysis of spike times. Different firing patterns may reflect nontrivial neuronal coding properties. An earlier study has indicated some units in the cat parahippocampal gyrus fired different patterns during electrical stimulation at various limbic locations ${ }^{3}$. That certain units in this limbic gyrus generated patterns with different time characteristics during nonstimulation periods is to be demonstrated in the present study. The intent of this investigation was not to attempt classification of the firing patterns arising from the 30 cell types ${ }^{8}$ in this gyrus but to develop a better appreciation of a few discharge patterns.

In the interval histogram all information about the time ordering of particular spike intervals is necessarily lost ${ }^{11}$. The sign of serial correlation coefficients provides for some insight on the relative sizes of spike intervals in a series ${ }^{10,13}$. The autocorrelation presents an average for evaluating spike occurrence as a function of time. However, when more than one pattern recurs the temporal properties of a given type sequence may be obscured in the autocorrelation display. Analytical methods for demonstrating different patterns in a spike train are presented in this report.

\section{METHODS}

Data samples were obtained from 18 unanesthetized artificially respirated curarized cats weighing from 2.0 to $3.5 \mathrm{~kg}$. A previous report gives details on animal surgical and care procedures employed ${ }^{3}$. Any pain which would result from pressure and incision points was blocked locally with procaine hydrochloride anesthetic. Unit discharges, sampled with stainless steel microelectrodes ${ }^{5}$, were recorded on moving film. The discharge activity was spontaneous in that no known stimulus was intentionally applied to the preparation during the recording of the sampled activity. Discharge records were obtained from 25 units. Samples of spike activity 1-5 min (547-1488 spikes) in duration were analyzed later. Upon completion of a unit re- 


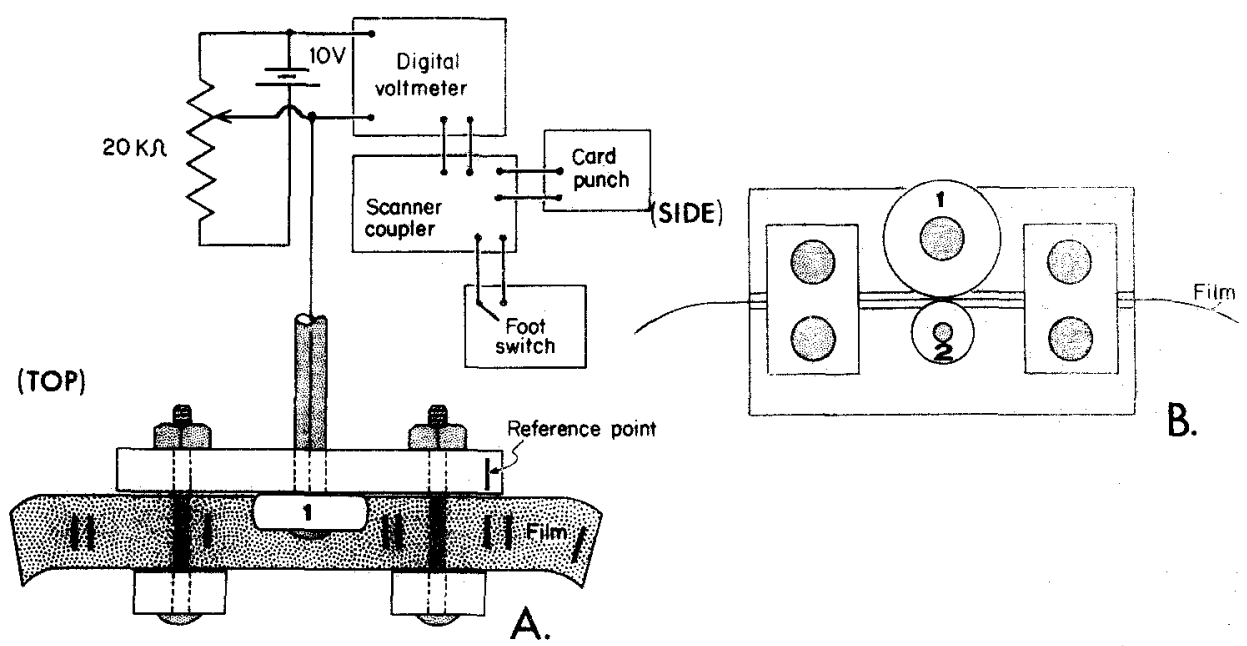

Fig. 1. Schematic of digitizing equipment. The $35 \mathrm{~mm}$ film, previously exposed at a known uniform rate, was held firmly between 2 rubber wheels mounted to a plastic film guide (A and $B$ ). Axle of wheel 2 was connected to a linear 10 turn potentiometer. Turning wheel 1 advanced film and changed resistance across potentiometer. When film pulse coincided with reference point on film guide voltage value was punched on card. Multiplying difference value of consecutive recordings by time per unit voltage constant gave an interval time value. Interval values were calculated by computer processing the data.

cording session a direct current was passed through the microelectrode. Small iron deposits from the electrode tip were demonstrated according to a previously described technique ${ }^{6}$. Paraffin sections, $20-40 \mu \mathrm{m}$ in thickness, were stained with basic fuchsin ${ }^{12}$, and the tissue location of the iron deposit indicating the cortical location of the unit were histologically investigated.

Interspike interval times were manually digitized (Fig. 1). The measurement resolution was $10 \mathrm{msec}$. Computer programs were written in Fortran IV. The computer facilities at The University of Michigan processed the data.

\section{ANALYTICAL PROCEDURES}

Previous reports give the mathematics pertinent for computation of an estimate of the autocorrelation for a train of spikes (a series of delta functions) ${ }^{4}$. Time measurements were made from a spike to following spikes. In a train of $N$ spikes, $N-1$ spikes served as a zero time reference origin. For the spike train, all nth-order intervals of duration less than the maximum lag time, $1000 \mathrm{msec}$, were measured. An nthorder interval, as stated previously ${ }^{9}$, is the interval from a spike to the nth following spike in the series. In the autocorrelation interval histogram, $z_{k}$, the ordinate value of the kth plot character, collectively equals the number of intervals of duration between $(\mathrm{k}-1) \Delta$ and $\mathrm{k} \Delta$ time units. Intervals of different orders may be represented in a given time bin (class interval). The binwidth or $\Delta$, the time segment of resolution, was 10 msec. The zero time lag count, equal to the number of spikes in the train, was not plotted.

Brain Research, 18 (1970) 527-537 
The nonspecification of the order interval for any given time bin does not permit the autocorrelation to specify any one spike sequence. The timing of future spikes in a series may depend upon influences initiated by cellular activity during the unit's firing history. Let an interval, I, be defined by a zero time reference spike and by some selected time, ST, following the spike. ST was selected as a time greater than the initial peak firing time seen on the autocorrelation interval histogram. Let ST and the maximum lag time define a post interval, PI. After I or during PI are the chances for spike occurrence over time similar irrespective of whether or not at least one spike occurred in I? A comparison of the ordinate values at corresponding times on the 2 types of histograms to be described below aids one in answering this question.

The condition interval histogram, $\mathrm{CIH}$, represents all spike sequences in the train where at least one spike occurred in I and spikes may have occurred in PI. Stated in a more formal manner, let the spikes in the train be represented as $\mathrm{j}=0$, $1, \ldots, N$ where $\mathrm{j}=0$ is the first and $N$ the last spike of the series. Let $\mathrm{k}=1,2, \ldots$, $N$ be the $\mathrm{j}-1, \mathrm{j}-2, \ldots, N$ spike of the series. Take the $\mathrm{j}$ spike as the origin of the time axis. Let $t_{j}=0$. Let $I$ be some selected interval greater than 0 . For all $k$

$$
\Delta(\mathrm{j})=\begin{aligned}
& 1,\left(\mathrm{t}_{\mathrm{j}+1}-\mathrm{t}_{\mathrm{j}}\right) \leq \mathrm{I} \\
& 0,\left(\mathrm{t}_{\mathrm{j}+1}-\mathrm{t}_{\mathrm{j}}\right)>I
\end{aligned}
$$

The 2 condition interval histogram, TCIH, represents all sequences in the train where 2 conditions were met. The 2 interspike intervals defined, in part, by the zero time reference spike had to be of duration greater than $\mathrm{I}$. That is, for all $\mathrm{k}$

$$
\Delta(\mathrm{j})=\left\{\begin{array}{l}
1,\left(\mathrm{t}_{\mathrm{j}+1}-\mathrm{t}_{\mathrm{j}}\right)>\mathrm{I} \\
\text { and } \\
\left(\mathrm{t}_{\mathrm{j}}-\mathrm{t}_{\mathrm{j}-1}\right)>\mathrm{I} \\
0,\left(\mathrm{t}_{\mathrm{j}+1}-\mathrm{t}_{\mathrm{j}}\right) \leq \mathrm{I}
\end{array}\right.
$$

Fig. 2 illustrates spike patterns included in the different types of histograms. Patterns A, B and C were represented in the autocorrelation interval histogram. Pattern A was represented in the $\mathrm{CIH}$ because a spike occurred in I. Pattern B was not represented in the $\mathrm{CIH}$ or $\mathrm{TCIH}$, because for the first case no spike occurred in I and for the 2nd case the zero time spike bounds an interval of duration less than I. Pattern $\mathrm{C}$ was represented in the $\mathrm{TCIH}$, because the 2 interspike intervals bounded, in part, by the zero time spike were of duration greater than I (boundary of interval preceding $t=0$ spike not shown). Segments or portions of each of the 3 patterns could be represented in both the $\mathrm{CIH}$ and TCIH depending upon the spike configurations when different zero time reference spikes were employed for the measurements.

DATA ANALYSIS

The major characteristics of histograms representing the spike data are presented in Table I. Unimodal interspike interval histograms for 20 units illustrated peaks 


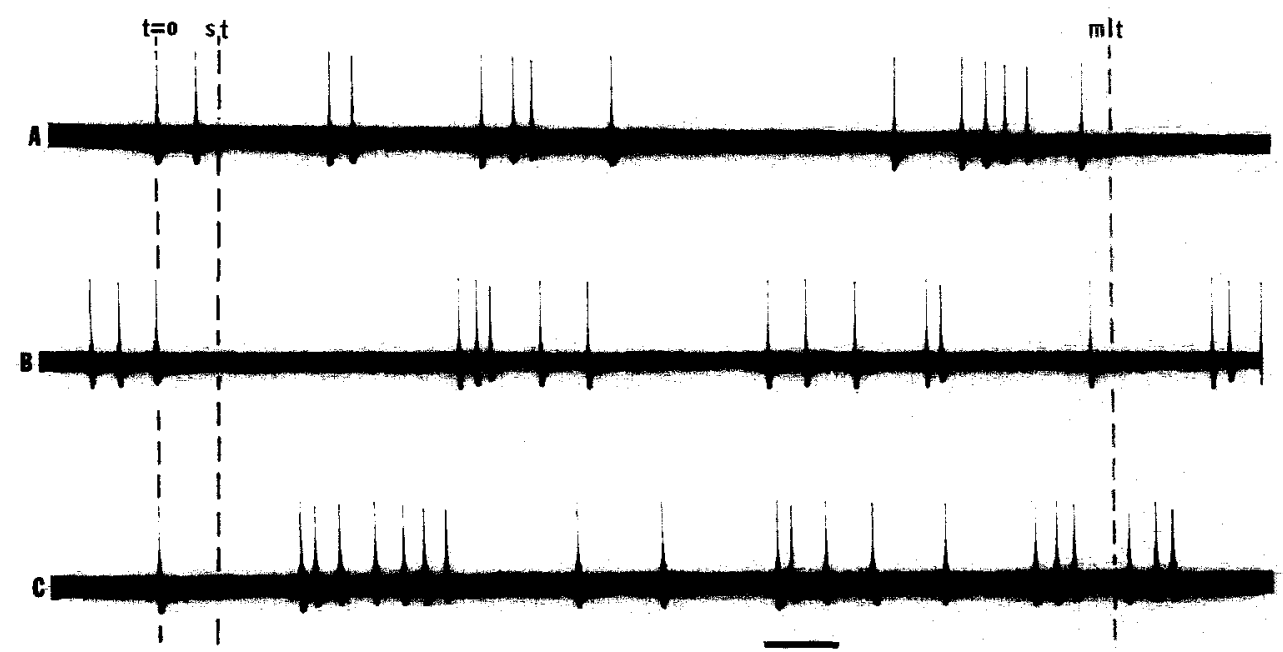

Fig. 2. Unit P 23-2 spike patterns. Zero time reference spikes for sequences $A, B$, and $C$ located at zero time $(t=0)$. Selected time (st) and maximum lag time (mlt) were times used in analyzing spike data. See text. Time bar $=67 \mathrm{msec}$.

200.000

AUTOCORRELATION (1) NOD COMDITIOA (2) IMTERVL HISTCGRAMS

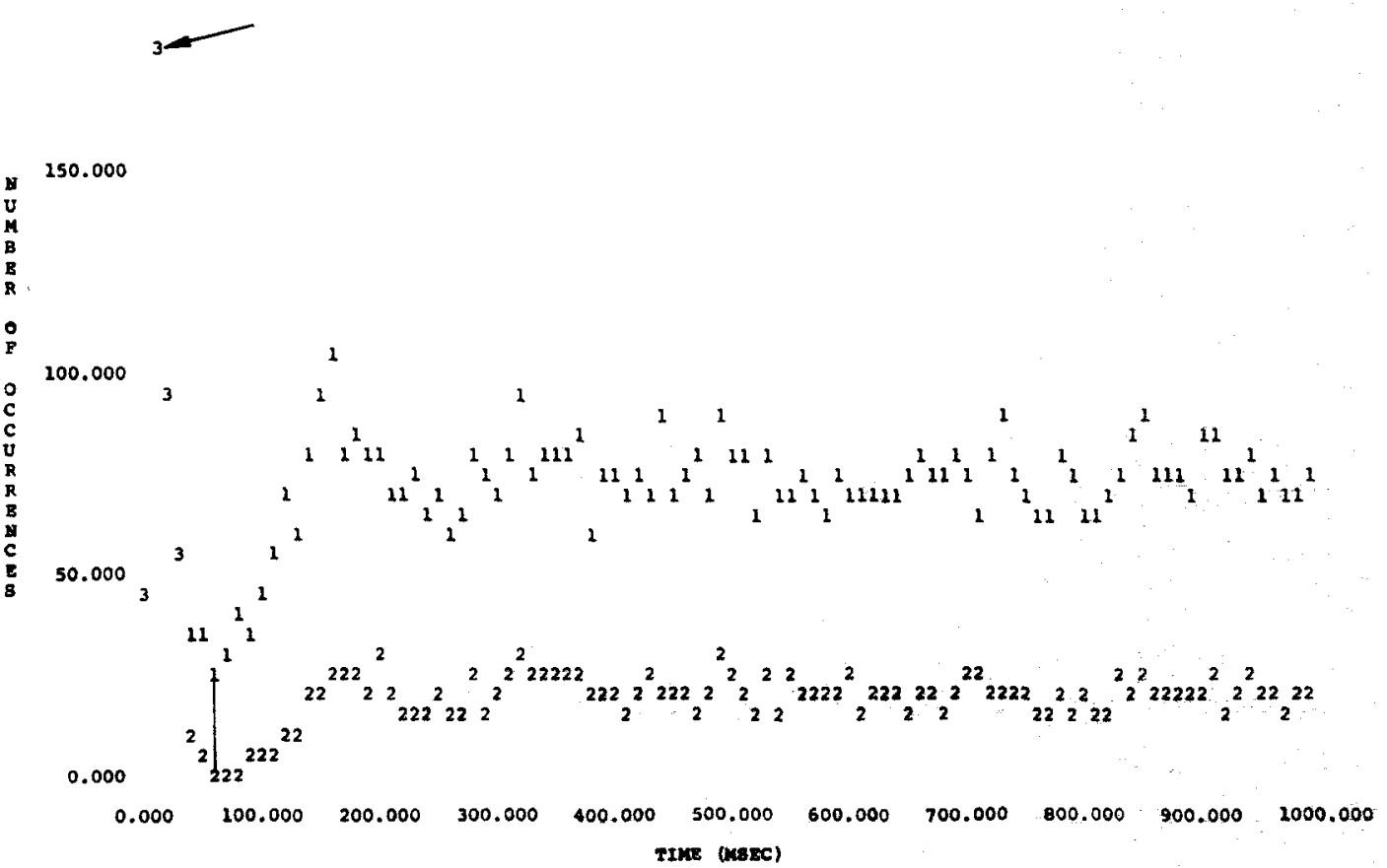

Fig. 3. Unit P 30-6 data. Plot character 3 represents spatial location for characters 1 and 2. Arrow indicates peak at $10-20 \mathrm{msec}$ and vertical bar connects minimum points at $60-70$ msec. Mean interspike interval $158 \mathrm{msec}, 1204$ spikes, 339 interspike intervals less than $40 \mathrm{msec}$. Selected time for condition interval histogram $40 \mathrm{msec}$. See text.

Brain Research, 18 (1970) 527-537 


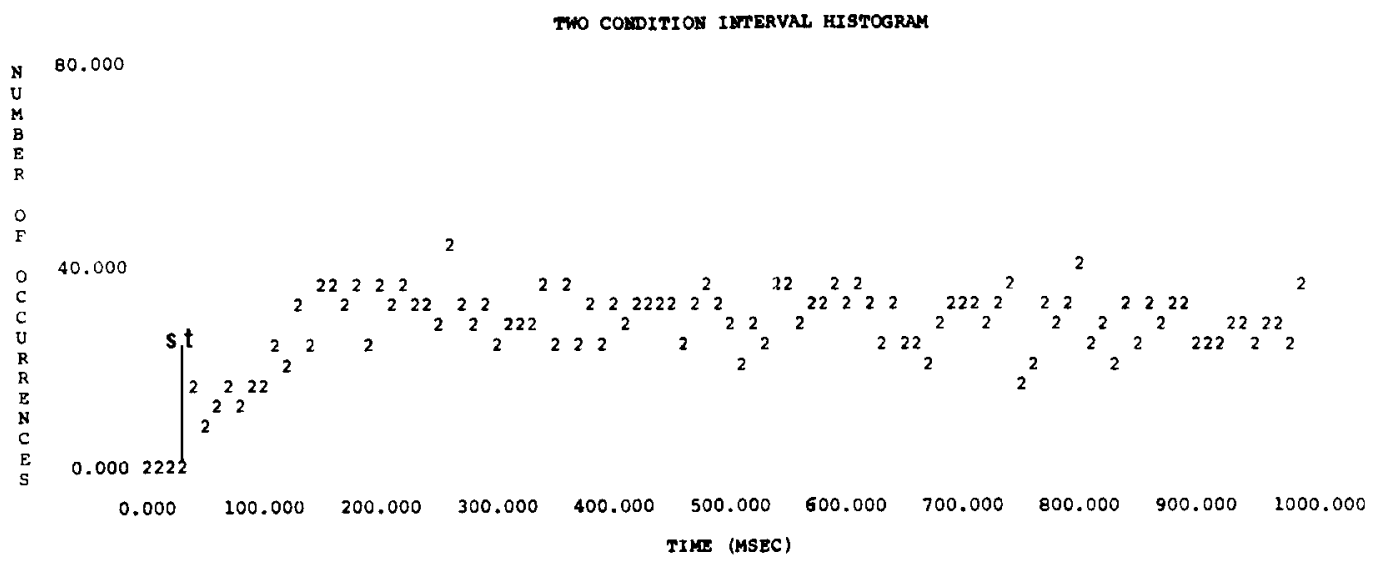

Fig. 4. Unit P 11-1 data. Mean interspike interval $182 \mathrm{msec}$, interspike interval preceding and following 481 of 1268 spikes was of duration greater than $40 \mathrm{msec}$. Selected time (st) $40 \mathrm{msec}$. See text.

between 20 and $60 \mathrm{msec}$ or at $90-100 \mathrm{msec}$ and were skewed to the right. Peaks on histograms for 5 units were at $10-40 \mathrm{msec}$ and at $100-120 \mathrm{msec}$ or $170-210 \mathrm{msec}$.

The description given of the autocorrelation interval histogram (Fig. 3) for the data from unit P 30-6 applies in a general way to the data from 7 units. The highest peak on the plot is at $10-20 \mathrm{msec}$ (range for 7 units $10-30 \mathrm{msec}$ ). The unit fired most frequently between 10-20 msec following the zero time firing. The peak is immediately followed by a deep dip or trough. The deepest part of the trough, indicating the period when the unit fired least frequently, is at $60-70 \mathrm{msec}$. A semiregular baseline follows the trough. The baseline, being nearly flat from 120 to $1000 \mathrm{msec}$, indicates the spike probabilities were nearly equal for all times in this period. For the 7 units, the baselines never began at times earlier than $110 \mathrm{msec}$, and each was preceded by a trough.

Were trough time or early PI $(40-90 \mathrm{msec})$ spikes in the 7 unit spike trains generally related to discharges occurring in I ( $1-40 \mathrm{msec})$ or were they part of a different spike sequence? To aid in answering this question one is referred to the $\mathrm{CIH}$ in Fig. 3. All sequences in the train where one or more spikes occurred during I are represented by counts in the I time bins (plot character 3) of the $\mathrm{CIH}$. The first 2 time bins in PI (plot character 2) have small ordinate values, whereas later ones have a zero value. Thus, when 2 or more spikes occurred within a $40 \mathrm{msec}$ period a spike would sometimes occur between 40 and $60 \mathrm{msec}$ but never between 60 and $90 \mathrm{msec}$ following the first spike of the sequence. Therefore, spikes occurring at $60-90 \mathrm{msec}$ were not preceded by a 1-40 msec spike. Spikes occurred after $90 \mathrm{msec}$. The distribution of plot characters is flat from approximately 150 to $1000 \mathrm{msec}$. Such patterns were found for 2 units, each in different animals. When the data from the other 5 units were plotted a small number of counts were found in the CIH dip time bins. In summary, for data from 7 units, spikes occurring within a $40 \mathrm{msec}$ period were not usually followed by a spike during a later $30 \mathrm{msec}$ period nor preceded by more than 1 spike during an earlier $40 \mathrm{msec}$ period (symmetry).

For the 7 units, spike probabilities during PI (40-1000 msec) may have been related to cellular activity evoked by the zero time spikes. Two condition interval 
TABLE I

PARAHIPPOCAMPAL UNIT DISCHARGE ACTIVITY

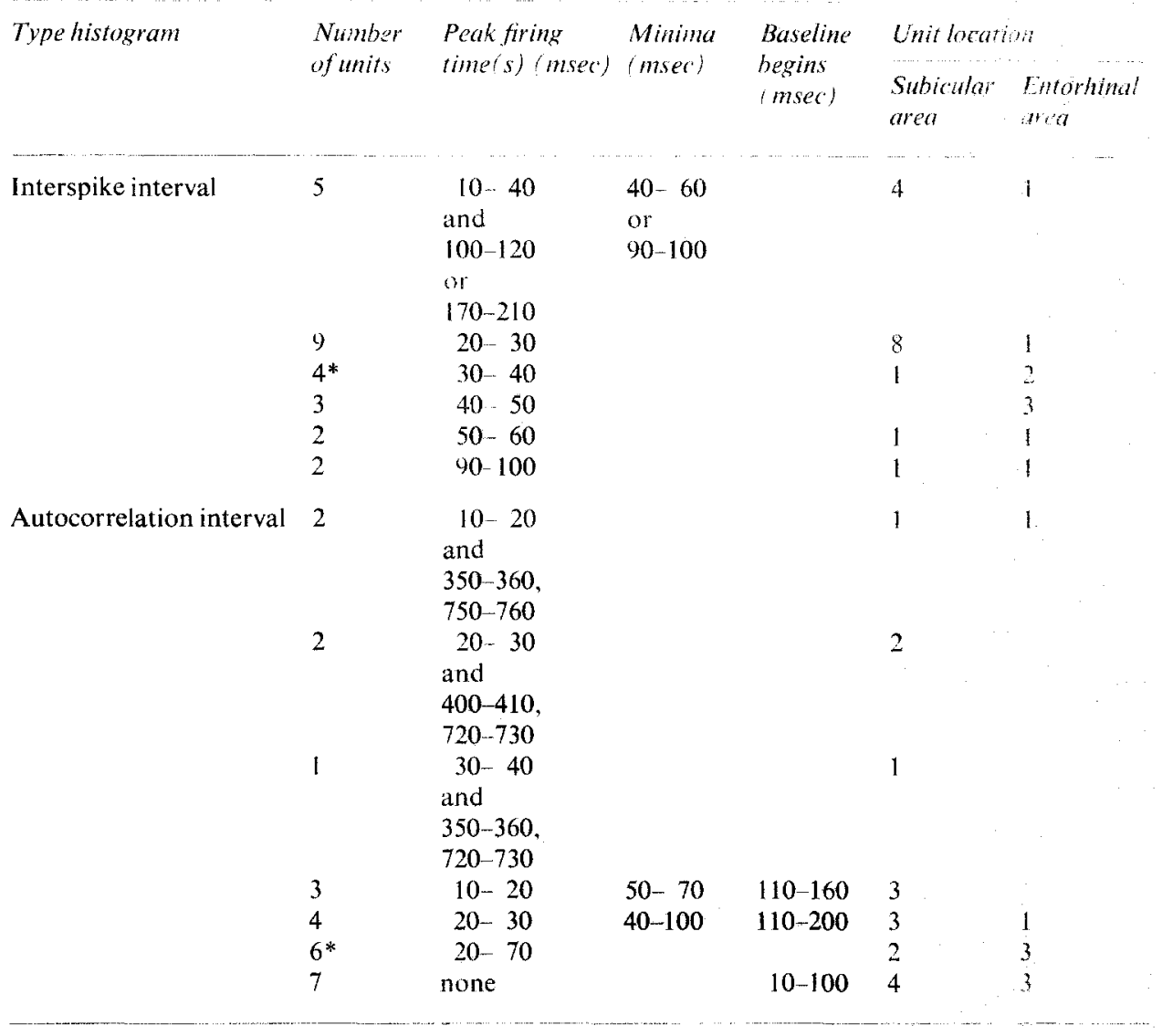

* One unit not located.

histograms were constructed. The TCIH (Fig. 4), where I was $40 \mathrm{msec}$, indicates the fewest number of intervals, and hence the smallest spike probabilities were in the early part of PI. Later in PI the plot character distribution is nearly flat. The smaller spike firing probabilities for the early PI times may not have been independent of activity concurrent with the zero time spike.

Other autocorrelation interval histograms showed multiple peaks. The peak time values are listed in Table 1 . The interspike interval histogram was unimodal for spike data sampled from unit P 23-2. Multiple peaks are illustrated on the autocorrelation histogram (Fig. 5). Peak values are found at approximately 30, 380 and $760 \mathrm{msec}$. As in the autocorrelation histogram, the CIH (Fig. 5), where I was $30 \mathrm{msec}$, illustrates peaks at similar timejulues. Therefore, when 12 or more spikes occurred within a $30 \mathrm{msec}$ period more spikes, on the average, occurred at 380 and $760 \mathrm{msec}$ following the first spike than at other times. For the same spike train, where I was $30 \mathrm{msec}$ the TCIH (Fig. 6) has a nearly flat distribution. As could be expected, in 
250.0003

200.000

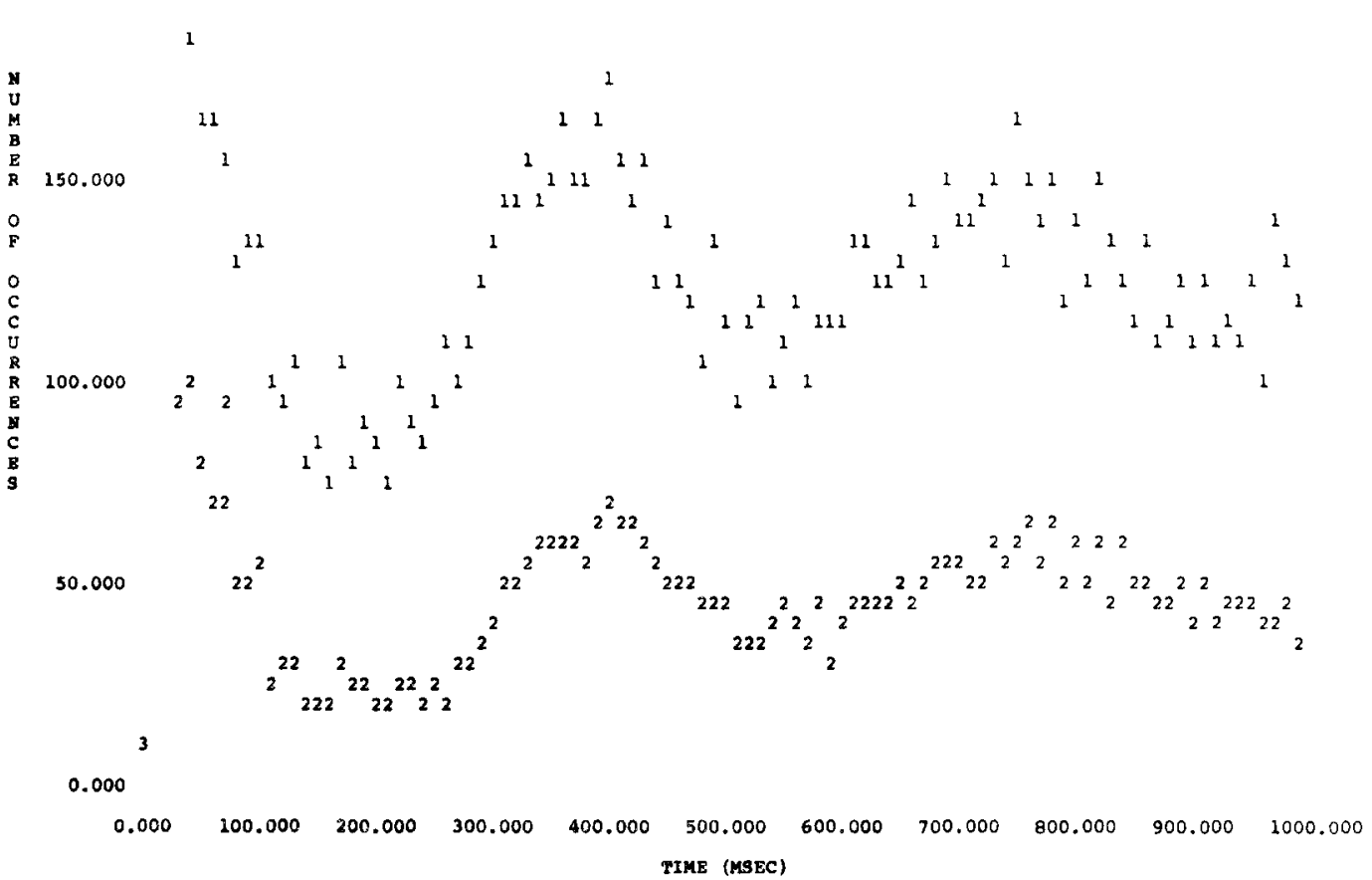

Fig. 5. Unit P 23-2 data. Plot character 3 represents spatial location for characters 1 and 2. Mean interspike interval $97 \mathrm{msec}, 1238$ spikes, 463 intervals less than $30 \mathrm{msec}$, selected time for condition interval histogram $30 \mathrm{msec}$. See text.

the $\mathrm{TClH}$ (not shown) where I was less than $30 \mathrm{msec}$ multiple peaks occurred. When the interval between 2 spikes was $30 \mathrm{msec}$ or greater then the probabilities for future spikes were nearly equal for all times $(30-1000 \mathrm{msec})$.

Subjecting the sample of interspike intervals to random shuffling destroys the serial dependence but preserves the order-independent statistics of the sample ${ }^{10}$. Condition interval histograms for shuffled unit data are illustrated in Fig. 7. In each histogram the early peak is at ordinate and abscissa values nearly similar to those in the CIH histograms (Fig. 3 and 5) of the unshuffled data. The spike data contributing to the early peak were not order-dependent. The early peak in each of the autocorrelation histograms (Figs. 3 and 5) and in the shuffled condition interval histograms (Fig. 7) represents, for the most part, first-order intervals. This can be easily demonstrated by comparing ordinate values of the peaks with those on interspike interval histograms (not shown). For unit P 23-2 no dip or peak follows the initial peak on the CIH for shuffled interval data. The peaks at 380 and $760 \mathrm{msec}$ in 


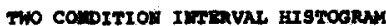

100.000

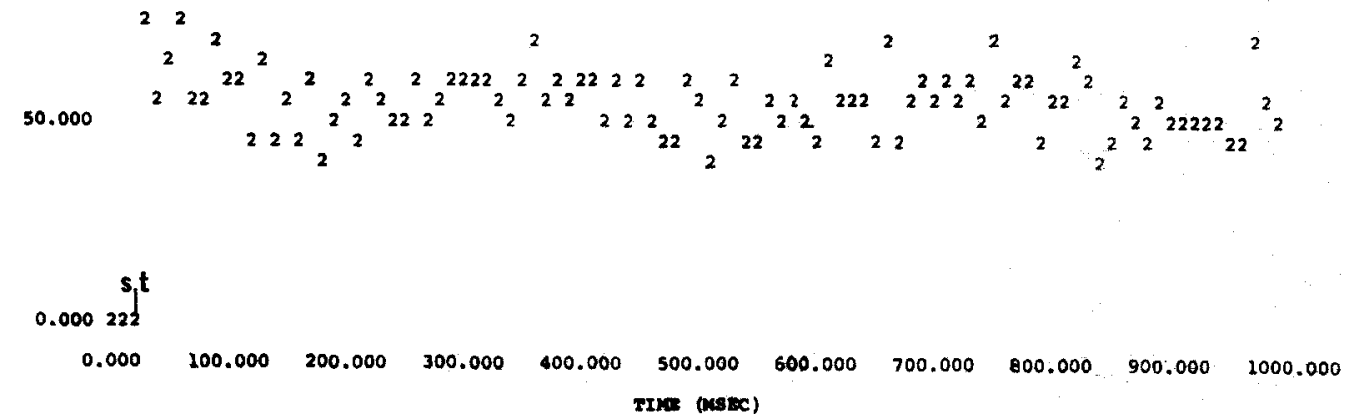

Fig. 6. Unit P 23-2 data. Mean interspike interval $97 \mathrm{msec}, 1238$ spikes, interspike interval preceding and following 515 spikes was of duration greater than $30 \mathrm{msec}$, selected time (st) $30 \mathrm{msec}$. See text.

250.000

SHUYTLED COEDITION IMTERVAi HISTOORAMS

200.000

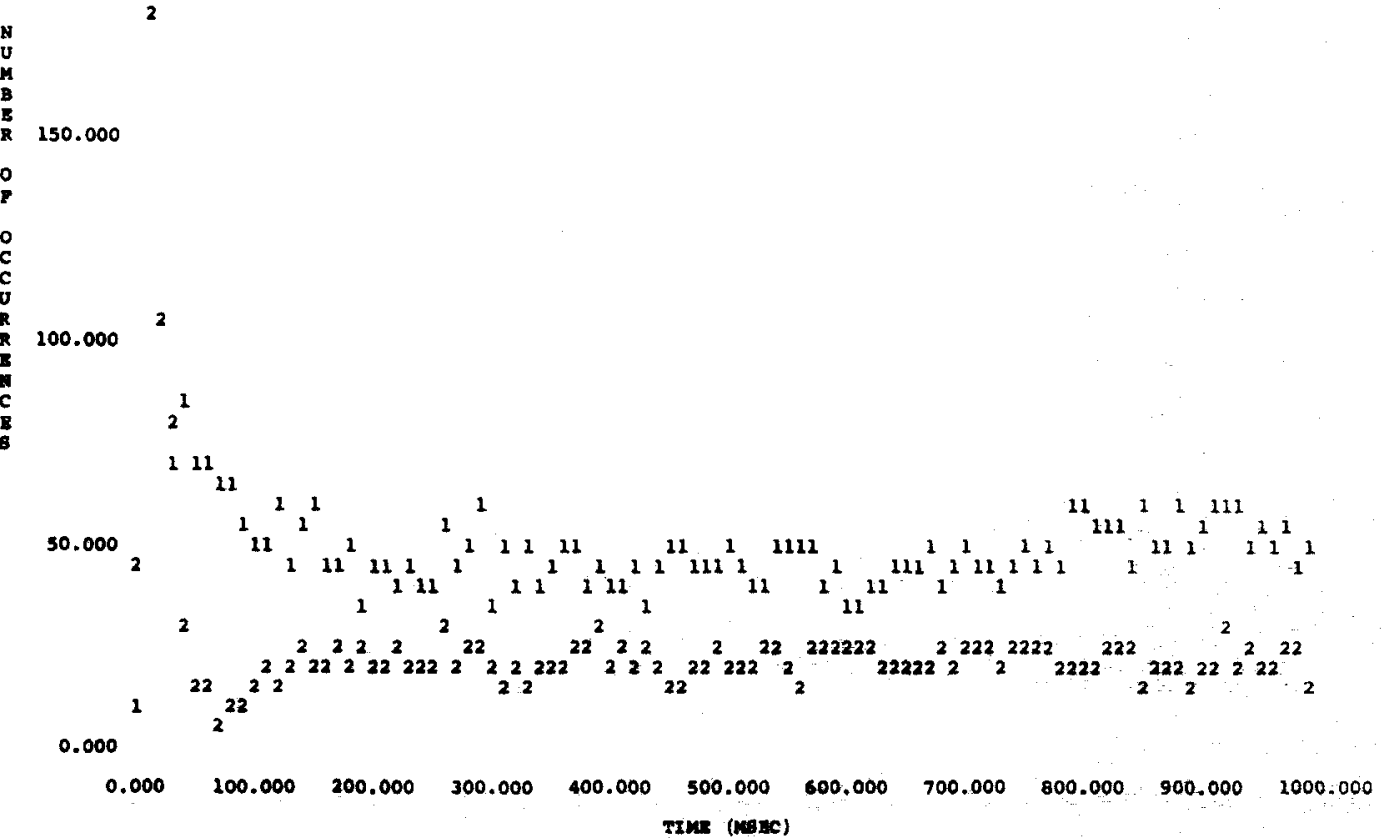

Fig. 7. Unit $P$ 23-2 and $P$ 30-6 data. For unit $P$ 23-2, plot character 1, 463 interspike intervals less than $30 \mathrm{msec}, 1238$ spikes, selected time $30 \mathrm{msec}$. For unit $P$ 30-6, 338 interspike intervals less than $40 \mathrm{msec}, 1204$ spikes, selected time $40 \mathrm{msec}$. See text.

Brain Research, 18 (1970) 527-537 
the autocorrelation histogram (Fig. 5) were interval order-dependent and were not the result of unsummed first-order interval measurements.

Seven other autocorrelation interval histograms illustrated flat baselines beginning between 10 and $100 \mathrm{msec}$ and continuing to $1000 \mathrm{msec}$. The spike firing probabilities were nearly equal for all times.

Twenty-four of the 25 cells were located histologically. Fifteen were in the subicular area, and the remainder were in the entorhinal area. Different cortical layers were represented, but a classification of the layers by patterns is not justified by virtue of the small sample size. Moreover, the extracellular recording technique employed favored sampling of the larger cells.

COMMENTS

Various physiologic integrating processes are probably represented in the data displayed on autocorrelation interval histograms. Peaks on histograms indicate times when inputs most frequently triggered the spike generators. Dips represent times when the units fired least frequently. The time course of an active inhibition preventing firing would be indicated by a dip. A flat autocorrelation indicates an equal likelihood for firing at all times.

For 7 units, the smaller spike probabilities at times greater than $60 \mathrm{msec}$ (TCIH Fig. 4) were probably independent of refractory influences evoked by earlier spikes. The peak firing times, being at times less than $30 \mathrm{msec}$, suggest the refractory influences from a spike limited firing for a period less than $30 \mathrm{msec}$. The nonfiring period from 60 to $90 \mathrm{msec}$, sometimes preceded by spikes in the $40-60 \mathrm{msec}$ period, began too late and was too long to be accounted for by refractory influences evoked by a spike in the $1-40$ msec period. Obviously, the spike generators did not receive sufficient excitatory inputs to be fired. That the cell received fewer excitatory inputs during the $60-90 \mathrm{msec}$ period than at other times is possible. Receiving fewer inputs at $60-90 \mathrm{msec}$ would mean the cell's input was time-coupled to its generators' output, otherwise the dip would not be present. Parahippocampal cells have many inputs ${ }^{8}$, each probably contributing at a different time. More likely, feedback inhibitory influences, similar to inhibitory postsynaptic potentials in the hippocampus ${ }^{2,7}$ and summing over time, may have most effectively limited firing at times between 40 and $60 \mathrm{msec}$ following each spike. A large percentage of sampled parahippocampal units stopped firing during septal stimulation ${ }^{3}$. The $40 \mathrm{msec}$ time between a spike and a probable feedback could be accounted for by a pulse having to travel a long distance and at a slow conduction rate.

Autocorrelation interval histograms illustrating multiple peaks apparently represent complex regulatory activities. The peaks, dependent upon the serial arrangement of intervals in the train, indicate some order prevails in the series. The periodic spikes, possibly associated with the parahippocampal slow wave activity ${ }^{1}$, appear to be driven from a signal source independent of the one evoking the intervening jittered spikes. 


\section{SUMMARY}

Twenty-five cat parahippocampal gyrus unit spike trains were analyzed for firing time characteristics. Autocorrelation interval and 2 new types of histograms displayed data sampled from spontaneously firing units. For 7 units, spikes occurring within a $40 \mathrm{msec}$ period were not generally followed by a spike in the $40-90 \mathrm{msec}$ period following the first spike. Evoked feedback inhibitory influences, being most effective at $40-60 \mathrm{msec}$ following each spike and summing over time, may account for the 40-90 msec zero or small firing probabilities. Spikes occurred between $60-90$ msec following a previous spike but were not generally preceded by a firing in the $1-40$ msec period.

In other trains, spikes occurring within a $30 \mathrm{msec}$ period were followed most frequently by a spike or spikes in the $350-410 \mathrm{msec}$ period following the first firing. When the interval between 2 firings was greater than $30 \mathrm{msec}$ probabilities for future spikes were nearly equal for all times up to $1000 \mathrm{msec}$. Autocorrelation interval histogram peaks at $350-410 \mathrm{msec}$ intervals were dependent upon the serial arrangement of intervals in the train. Inputs, evoking 2 or more firings within a 30 msec period, may have been periodically impressed on the cells.

\section{ACKNOWLEDGEMENTS}

The spike train data were obtained under project support from the National Institutes of Health NB 05069, Dr. Charles Votaw, chief investigator. The author wishes to thank The University of Michigan for providing computer time. A University of Michigan Faculty Research Grant provided for computing and manuscript supplies.

\section{REFERENCES}

1 Adey, W. R., Dunlop, C. W., And Hendrix, C. E., Hippocampal slow waves. Distribution and phase relationships in the course of approach learning, Arch. Neurol. (Chic.), 3 (1960) 74-90.

2 Andersen, P., ECCles, J. C., AND LgYNing, Y., Location of postsynaptic inhibitory synapses on hippocampal pyramids, J. Neurophysiol., 27 (1964) 592-607.

3 COYLE, $\mathrm{P}$., Cat parahippocampal unit discharge patterns during limbic stimulation, Brain Research, 15 (1969) 175-183.

4 Gerstein, G. L., AND Kiang, N. Y.-S., An approach to the quantitative analysis of electrophysiological data from single neurons, Biophys. $J ., 1$ (1960) 15-28.

5 GreEN, J. D., A simple microelectrode for recording from the central nervous system, Nature (Lond.), 182 (1958) 962.

6 Green, J. D., Mancia, M., and von Baumgarten, R., Recurrent inhibition in the olfactory. bulb. I. Effects of antidromic stimulation of the lateral olfactory tract, $J$. Neurophysiol., 25 (1962) 467-488.

7 Kandel, E. R., Spencer, W. A., AND Brinley, F. J., JR., Electrophysiology of hippocampal neurons. I. Sequential invasion and synaptic organization, J. Neurophysiol, 24 (1961) 225-242.

8 LORENTE DE Nó, R., Studies on the structure of the cerebral cortex. l. The area entorhinalis, J. Psychol. Neurol. (Lpz.), 45 (1933) 381-438.

9 Moore, G. P., Perkel, D. H., and Segundo, J. P., Statistical analysis and functional interpretation of neuronal spike data, Ann. Rev. Physiol., 28 (1966) 493-522. 
10 Perkel, D. H., Gerstein, G. L., And Moore, G. P., Neuronal spike trains and stochastic point processes. I. The single spike train, Biophys. J., 7 (1967) 391-418.

11 Rodieck, R. W., Kiang, N. Y.-S., and Gerstein, G. L., Some quantitative methods for the study of spontaneous activity of single neurons, Biophys. J., 2 (1962) $352-368$.

12 Szabó, I., Combined staining of central nervous system tissue with luxol fast blue and basic fuchsin, Acta morph. Acad. Sci. hung., 13 (1965) 251-254.

13 Wyman, R., Probabilistic characterization of simultaneous nerve impulse sequences controlling dipteran flight, Biophys. J., 5 (1965) 447-471. 